\title{
Ecological and economic aspect of sustainable agriculture development on the basis of effective land use planning and land cadastral works
}

\author{
Elena Denisova*, and Viktoriya Silova \\ FSC of Agroecology RAS, 400062 Volgograd, Russia
}

\begin{abstract}
Agriculture is a complex and unstable system, the successful development of which firstly depends on the purposeful and integrated interaction of natural, social and historical conditions. Land cadastral provision acts as a guarantor of agricultural production growth, builds a socially favorable environment for the development of economic processes planned by the state. The aim of the study was to substantiate the need to improve the organizational and economic mechanism of agricultural land registration, land management and land cadastral works. Degradation processes, which have become widespread in the territory of Staropoltavsky district of Volgograd region - deflation $(20.8 \%$ of agricultural land area) and salinization (30.8\%) have impact on living standards and population numbers. The presence of unused arable land in $67 \%$ of rural settlements indicates the inefficiency of the monitoring and accounting system, and the presence of $39 \%$ of low-productive land indicates the untimely implementation of rehabilitation and reclamation work. The established value of the cadastral land value specific indicator (CLVSI) determines the system of economic impact in the form of land tax, rent, and other payments. The CLVSI value does not correspond to the arable quality in $50 \%$ of territory. With the help of geoinformation technologies, the boundaries and area of 16 neighborhoods and 8 settlements within the Gmelinsky rural settlement were confirmed, the total area of which is 1359.0 ha. The decrease in area amounts to $1.0 \%$. The discrepancy in land areas according to statistical data and estimate materials amounted to 38329 hectares or $68.5 \%$.
\end{abstract}

\section{Introduction}

The agro-industrial complex is a defining indicator that characterizes the state of the entire economy of the country. Its development and stability are impossible without an ecological, social, recreational and cultural environment in each individual region. Over the past decades there has been a reduction in the AIC resource potential and the ecological

\footnotetext{
${ }^{*}$ Corresponding author: denisov.00@mail.ru
} 
condition degradation of arable land. More than $70 \%$ of the land is subjected to wind and water erosion, $20 \%$ of soils are overwetted and waterlogged, $8 \%$ - salinated, $44 \%$ - have high acidity, 95 million hectares are characterized by low humus content.

However, despite the crisis, there is a significant unused potential in agriculture in the form of abandoned and low-productive land. Institutional transformation, particularly in the field of land relations, are needed to improve the efficiency of agricultural land use to prevent their degradation and exclusion from rotation [1].

Being actively involved in agricultural production, the land acts as an object of labor and an instrument by which a person produces the products he needs. Current trends in the land resources use are expressed in the wide intensification of the productive lands use, involvement of additional land areas in the economic circulation, expanding the diversion of land for non - agricultural needs, increasing the number of transactions with individual land plots. In this case, the need for a thorough and timely inventory of land availability and distribution, as well as an assessment of land resources usage efficiency [2] is clearly indicated.

\section{Materials and methods}

The sustainable development of agricultural production implies a symbiosis of all spheres of science and production - legal, political, organizational, economic, environmental and social, which form and define this concept. The use of land resources in the agricultural sector of the country must be considered comprehensively and in detail with the solution of a number of tasks:

- monitoring and accounting;

- assessment of the current state of resource potential;

- ways to improve the quality of land resources;

- application of an environmental protection and soil protection measures system;

- economic stimulation of land owners and users.

The theoretical and methodological basis of this research consists of scientific and applied developments by Vershinin V. V., Volkov S. N., Papaskiri T. V., Sagaydak E. A., Khlystun V. N., which are devoted to the problems of assessing the efficiency of agricultural land use and improving their quality in intensive land use conditions.

In modern economic conditions of agro-industrial complex development and digitalization of many branches of agricultural production, the most relevant methods of obtaining information on the quantity, areas, structure and quality condition of agricultural land is cartographic geoinformation support based on aerospace research and computer modeling methods [3].

Geoinformation technologies solve and implement complex tasks for agrolandscapes modeling, such as linking objects on the map and terrain; determination of area and linear dimensions of individual landscape elements and agricultural land; creation of threedimensional terrain models, etc. The information obtained through space digital imaging is geographically comprehensive, modern, relevant and in demand, on which thematic maps displaying the state and position of the study objects are created. Such maps are compiled on a digital topographic model of space images in the GIS environment in the form of thematic cartographic and attribute layers (in MapInfo, GlobalMapper programs, etc.) [4].

To date, space images represent the most important source of objective information about objects of study. The most research-available are space images from the satellites Resurs P, Canopus, Worldview 3, Sentinel 2, Landsat-7, Landsat-8, etc., and data of global digital terrain models that allow for the full range of research related to obtaining information on the condition, quality and use of agricultural land. 


\section{Results and discussion}

The inefficient use of agricultural land, fragmentation and unsustainable size of land plots, lack of owner's interest and lack of financing leads to that natural and productive resources affecting the socio-economic development of the agro-industrial complex have an impact on the standard of living of the population, reduce investment attractiveness and impede the potential realization of each municipality [5]. On the example of the Staropoltavsky district of Volgograd region, the imperfection of land cadastral support, monitoring and accounting of agricultural land system forming ecological, social and economic sphere of the region is shown.

Staropoltavsky district of Volgograd region is located in the northeastern part of the Volgograd region and is characterized by a significant area of agricultural land - 343.6 thousand hectares (second place among municipal districts) and a significant share of arable land - 245,47 thousand hectares. Average annual precipitation reaches $300-330 \mathrm{~mm}$, high and unstable temperatures, low humidity - all of it affects the scarceness of forage lands and does not contribute to high and stable harvests in agro-industrial production. The area terrain is represented by gently rolling watersheds and plain beams cut with small eriks. The area water supply is insufficient, which also has an impact in crops cultivation on irrigation. The main soil types of the district are represented by chestnut alkali and chestnut medium-deep soils ( $23 \%$ and $20 \%$, respectively).

According to the territory survey results of the Staropoltavsky region, 34135.0 hectares of erosion threatening lands (about 10\% of the total area) of strong and moderate erosion degree were revealed. Deflationary threatening lands occupy $20.8 \%$ of the farmland area. The processes of overwetting and waterlogging have not been spread in the area and are $0.3 \%$ and $0.2 \%$ respectively. $30.8 \%$ of the agricultural land is subject to salinity, of which $16.6 \%$ are of medium degree, and salt-marshes have spread over an area of 4553.0 hectares $(4.3 \%)$.

The lands condition imprints the nature and intensity of their use, even in the context of the region itself. The municipality includes 18 rural settlements and 40 localities. The greatest loss of soil fertility can be observed in Krasnoyarskiy rural settlement $-34.4 \%$. The high level of land subject to flooding is shown by Gmelinsky settlement $-48.5 \%$. Territories with a high salinization degree are Verkhnevodyanskoye - $22.7 \%$ (of the total area of salted arable land), Saltovskoye - 21.6\% and Kanovskoye - 27.2\%. It is important to note that Verkhnevodyanskoye and Saltovskoye formations are located in the northern part of the region on the border with Saratov region, and Kanovskoye settlement is located in the south and borders with Pallasovsky district, which explains their high salinity.

The quality condition of the land has a direct impact on the standard of living and the number of population in each municipal entity, builds the social and educational environment, forms economic policies of the entire region. The ecological condition of the obtained agricultural products determines the food market and the competitiveness of food products.

On the territory of the district there is arable land, which has not been used for more than 2 years due to a number of reasons - poor lan quality, distance from the administrative center, abandonment, etc. The biggest share of such land lies within the borders of Cherebayevsky rural settlement - 40.7\%. The largest amount of low-productive arable land is located within the boundaries of Novopoltavskoye and Kharkovskoye rural settlements - about $11.0 \%$.

The presence of unused and low-productive arable land in rural settlements of Staropoltavskoye district indicates inefficient and irrational use of the district's agrarian potential. $38 \%$ of municipal formations do not use about $28 \%$ of arable land for over 2 
years, $17 \%$ of the district's settlements do not involve $30 \%$ to $40 \%$ of arable land in agricultural circulation. This attitude towards the strategic resource of the country indicates the inefficiency of the monitoring and accounting system, the untimely implementation of reclamation and recovery of abandoned and low-productive land, inadequate funding of municipalities and subsidies for interested land users (table 1).

Table 1. Quality condition of agricultural lands by municipal settlements of Staropoltavskoye district of Volgograd region

\begin{tabular}{|l|c|c|c|c|}
\hline \multicolumn{1}{|c|}{$\begin{array}{c}\text { Name of } \\
\text { municipalities }\end{array}$} & $\begin{array}{c}\text { Agricultural land } \\
\text { area, ha }\end{array}$ & $\begin{array}{c}\text { Quality } \\
\text { score }\end{array}$ & $\begin{array}{c}\text { Un } \\
\text { used arable (more } \\
\text { than 2 years), } \\
\text { ha /\% }\end{array}$ & $\begin{array}{c}\text { Low-productive } \\
\text { arable land, } \\
\text { ha /\% }\end{array}$ \\
\hline Belyaevskoe & 11748,0 & 45 & $-/-$ & $910,0 / 7,7$ \\
\hline Valuevskoye & 16044,0 & 51 & $-/-$ & $970,0 / 6,0$ \\
\hline Verkhnevodyanskoye & 24956,0 & 61 & $5217,0 / 20,9$ & $574,0 / 2,3$ \\
\hline Gmelinskoe & 53699,0 & 36 & $15790,0 / 29,4$ & $400,0 / 0,7$ \\
\hline Ilovatskoye & 20328,0 & 39 & $5639,0 / 27,7$ & $2267,0 / 11,1$ \\
\hline Kanovskoye & 28064,0 & 24 & $8855,0 / 31,5$ & $1097,0 / 3,9$ \\
\hline Kolyshkinskoye & 12954,0 & 68 & $2522,0 / 19,4$ & $548,5 / 4,2$ \\
\hline Krasnoyarskoye & 8099,0 & 37 & $1919,0 / 23,7$ & $912,0 / 11,2$ \\
\hline Kurnaevskoye & 19552,0 & 61 & $4264,0 / 21,8$ & $260,0 / 1,3$ \\
\hline Lyatoshinskoye & 7148,0 & 20 & $-/-$ & $60,0 / 0,84$ \\
\hline Novokvasnikovskoye & 9788,0 & 29 & $285,0 / 2,9$ & $521,0 / 5,3$ \\
\hline Novopoltavskoye & 21296,0 & 66 & $41,0 / 0,19$ & $961,7 / 4,5$ \\
\hline Novotykhonovskoye & 29059,0 & 30 & $6285,0 / 21,6$ & $2726,8 / 9,4$ \\
\hline Saltovskoye & 18610,0 & 32 & $3753,0 / 20,2$ & $1905,0 / 10,2$ \\
\hline Staropoltavskoe & 8337,0 & 39 & $1381,0 / 16,5$ & $19,0 / 0,23$ \\
\hline Torgunskoye & 22531,0 & 50 & $7217,0 / 32,0$ & $506,0 / 2,3$ \\
\hline Kharkovskoye & 21231,0 & 36 & $8639,0 / 40,7$ & $769,0 / 3,6$ \\
\hline Cherebaevskoye & 8295,0 & 60 & $-/-$ & $351,5 / 4,2$ \\
\hline TOTAL & 340510,0 & 43,5 & $71806,0 / 21,1$ & $15759,1 / 4,6$ \\
\hline
\end{tabular}

\section{Conclusions}

No improvement in the system of accounting and maintenance of land cadastral works negatively affects the socio-economic development of the Staropoltavskoye district, which belongs to regional type I in development form, agricultural use, potential and features of rural formation. According to this classification, municipal settlements of the district are allotted with favorable natural and socio-demographic prerequisites for development, have intensive agricultural production ( $80 \%$ of goods produced), the share of agricultural land reaches $84 \%$ of the total area of the district.

The industry employs more than $70 \%$ of the population, which allows to provide work for the majority of Staropoltavskoye district's residents. Economic development and wellbeing of the district is based on favorable natural conditions, quality labor resources, rapid investment return and depends on the level of urban planning, social and production improvement. $42.5 \%$ of settlements are not expected to change the social and industrial 
sphere, weak urban planning changes are provided only in $30.0 \%$ of settlements. Moderate development is planned in the territory of 7 settlements (17.5\%) and involves the expansion of small and medium-sized forms of production. Only 4 settlements will be subject to active growth - Gmelinka, Nova Poltavka, Staraya Poltavka, Kharkovka villages, which reflects their potential. There is a comprehensive development of the population service areas planned, including the production sector.

The growth and recovery of agricultural production is impossible without the organization of a land accounting and management system, where each land plot has its unique natural and qualitative characteristics, purpose and legal use. Land management and land cadastral works are the most important integral part of the ecological and economic aspect forming sustainable agricultural production. The economic mechanism of land administration includes land tax, rent, market and collateral price of land, payments for environmental damage, etc., which are based on objective cadastral value.

On the territory of Staropoltavskiy district, an assessment of 1867 land plots of agricultural purpose was carried out with a total area of 850939,2 hectares. The weighted average cadastral value of the area land of this category is determined at the level of 9397.53 rubles/ha. The cadastral land value specific indicator (CLVSI) is established as the ratio of cadastral value of all land plots to the number of assessed objects in the context of each settlement (table 2).

Table 2. Comparison of specific indicators of cadastral land value (compiled by the author)

\begin{tabular}{|l|c|c|c|c|c|}
\hline $\begin{array}{c}\text { Name } \\
\text { of settlement }\end{array}$ & $\begin{array}{c}\text { Number } \\
\text { of plots }\end{array}$ & Area, ha & $\begin{array}{c}\text { Cadastral land } \\
\text { value specific } \\
\text { indicator } \\
\text { CLVSI, rub. /ha }\end{array}$ & $\begin{array}{c}\text { Rankings by } \\
\text { CLVSI }\end{array}$ & $\begin{array}{c}\text { Ranking } \\
\text { by } \\
\text { quality } \\
\text { score }\end{array}$ \\
\hline Belyaevskoe & 79 & 16015,5 & 7982,77 & 14 & 13 \\
\hline Valuevskoye & 18 & 20474,52 & 10934,1 & 4 & 10 \\
\hline Kolyshkinskoye & 91 & 19271,26 & 10257,68 & 7 & 1 \\
\hline Lyatoshinskoye & 113 & 8296,39 & 7974,53 & 14 & 8 \\
\hline Cherebaevskoye & 35 & 10903,11 & 8574,69 & 12 & 6 \\
\hline Novokvasnikovskoye & 32 & 2691,04 & 8004,8 & 13 & 12 \\
\hline Krasnoyarskoye & 56 & 11003,33 & 8878,69 & 11 & 3 \\
\hline Staropoltavskoe & 45 & 6260,91 & 10880,46 & 5 & 1 \\
\hline Verkhnevodyanskoye & 155 & 32560,38 & 8941,14 & 10 & 5 \\
\hline Novopoltavskoye & 100 & 28868,28 & 10149,24 & 8 & 2 \\
\hline Novotykhonovskoye & 167 & 51734,31 & 7301,98 & 15 & 30 \\
\hline Torgunskoye & 31 & 21924,52 & 9514,81 & 9 & 11 \\
\hline Kurnaevskoye & 144 & 28211,97 & 15038,34 & 2 & 5 \\
\hline Saltovkoye & 43 & 30258,94 & 6970,5 & 16 & 8 \\
\hline Kanovskoye & 182 & 49759,50 & 8882,8 & 11 & 8 \\
\hline Ilovatskoye & 223 & 31183,51 & 17995,2 & 1 & 4 \\
\hline Kharkovskoye & 96 & 36780,53 & 11534,94 & 3 & 7 \\
\hline Gmelinskoe & 208 & 94214,88 & 10644,84 & 6 & 9 \\
\hline Zero quarter & 46 & 350469,5 & 8690,76 & - & - \\
\hline Volgograd reservoir & 3 & 55,76 & 1437,92 & - & - \\
\hline Total by district & 1867 & 85093,2 & 9397,53 & & \\
\hline & & & & & \\
\hline & & & & & \\
\hline
\end{tabular}

The cadastral value of agricultural land in 9 rural settlements is lower than the average district value in the range of $5-10 \%$. In $40 \%$ of the district settlements exceedances are insignificant, in two municipalities the excess is $60 \%$ and $92 \%$ (Kurnaevskoye and Ilovatskoe).

Comparison of the ranking data by CLVSI and the quality score allows to conclude that the CLVSI value corresponds to the land quality only in $30 \%$ of municipalities. The lowest 
land quality in Novotykhonovsky rural settlement, which is confirmed by the CLVSI value, but this settlement has the largest area in relation to other settlements. In Valuevsky, Khar'kovskoye, Lyatoshinsky, Cherebaevsky, Krasnoyarsky, Staropoltavsky, Verkhnevodyanskoe, Novopoltavskoye and Saltovsky rural settlements, i.e. $50 \%$ of the territory of the studied area, CLVSI does not correspond to the land quality. In terms of land quality, Kolyshkinskoye municipal formation exceeds all others, and CLVSI value is at the level of the district average.

Gmelinsky rural settlement has such characteristics that distinguish it among others the largest area of agricultural land, the predominance of arable land not used for over 2 years, quality score close to the district average (36) and the highest total cadastral value of the assessed lands - more than one billion rubles.

Methods of obtaining quantitative data on cadastral quarters of Gmelinsky rural settlement were aerospace research in combination with geoinformation technologies and computer modelling, which together provide an idea of the location, areas, quantity of land, which contributes to the formulation of predictive measures within the boundaries of municipalities [6].

The boundaries and areas of 16 cadastral quarters, as well as 8 settlements within the Gmelinsky rural settlement were clarified, which corresponds to cadastral division. The area of the smallest quarter is 25.17 hectares, the largest - 18949.0 hectares, the perimeter of the settlement $-114.82 \mathrm{~km}$. The total area of the recorded settlements in the context of Gmelinsky municipality is 1359,0 hectares, the population is different and depends on the area of the settlement (Figure 1).

The area of Gmelinsky municipal formation has been subject to a downward change. In numerical terms, the decrease in the area of rural settlement occurs at a small rate (by 0.2 thousand hectares, 0.3 thousand hectares and 0.57 thousand hectares), and in percentage terms has a double increase of $0.03 \%, 0.05 \%$ and $1.0 \%$.

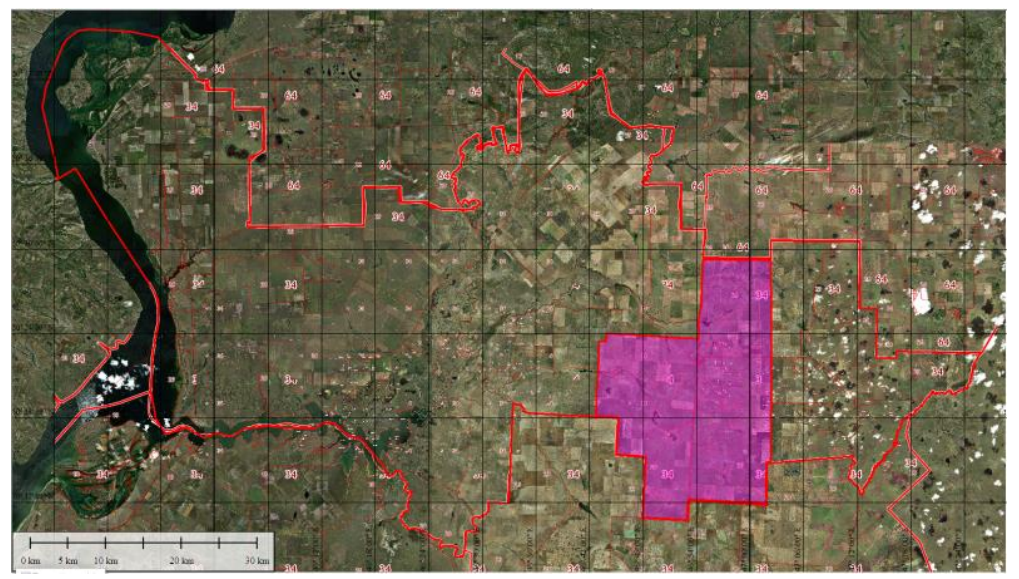

Fig. 1. Location of the Gmelinsky rural settlement on the space image

According to the data of the Federal Service of State Statistics, in 2019 the land area of Gmelinsky municipality amounted to 55885.0 hectares, and according to the materials of agricultural land assessment — 94214.88 ha, which exceeds the available area by 38329 hectares or $68.5 \%$.

The performed analysis gives reason to believe that the results of agricultural lands' cadastral assessment in the area require clarification. The situation with the divergence of available and estimated areas is observed in $90 \%$ of the district. The updated data will allow for more efficient management of land resources and balanced performance of work on land management and land-use planning. 
The settlement is characterized by a significant degree territory's tillage $-75 \%$ and a low coefficient of forest land of the territory - 0.03 . To improve the ecological stability of the territory and prevent the soil degradation development, a prerequisite is the design of a system of protective plantings, field-protecting afforestation [7].

On the basis of the settlements land fund analysis, contradictions between cadastral estimation and statistical records of lands are established. Objective data on the accounting and use of land resources cannot be obtained without specifying indicators on the condition and structure of the land fund, for this purpose it is necessary to carry out a full agricultural land inventory [8].

The mechanism for improving the efficiency of the agro-industrial complex should be based on modern methods of obtaining information on the state and use of natural resource potential, the accounting and monitoring system, development of planning and cartographic material and database creation, stimulating sustainable agricultural production, ensuring the rights of landowners and land users [9]. Economically developed agriculture can be obtained only with the combined implementation of these measures, which can form an economically stable state.

\section{References}

1. V.N. Khlystun, Herald of the Russian Academy of Sciences, 89(4), 325 (2019)

2. N.A. Borkhunov, E.A. Sagaydak, All-Russian Research Institute of Agricultural Economics, 184 (2011)

3. K.L. Lidin, M.G. Meerovich, E.A. Bulgakova, V.V. Vershinin, T.V. Papaskiri, Espacios, 39(1), 12 (2018)

4. E.V. Denisova, V.A. Silova, IOP Conference Series: Earth and Environmental Science, 52062 (2019)

5. K. Maler, Revista de Analisis Economico, 5, 7 (1990)

6. T.V. Papaskiri, A.E. Kasyanov, N.N. Alekseenko, V. N. Semochkin, E. P. Ananicheva, A.A. Shevchuk, The proceedings 2019th International Symposium on Earth Sciences: History, Contemporary Issues and Prospects, 012065 (2019)

7. P.V. Klyushin, V.N. Khlystun, A.V. Loshakov, S.V. Savinova, T.A. Ivanova, The proceedings 2019th International Symposium on Earth Sciences: History, Contemporary Issues and Prospects, 012034 (2019)

8. V.V. Vershinin, A.A. Murasheva, V.A. Shirokova, A.O. Khutorova, D.A. Shapovalov, V.A. Tarbaev, International journal of environmental, science education, 11(12), 5058 (2016)

9. S. Adrian, The Valuation Journal, 9(1), 54 (2014) 